\title{
Preimplantation factor is an anti-apoptotic effector in human trophoblasts involving p53 signaling pathway
}

\author{
Hadia Moindjie ${ }^{1}$, Esther Dos Santos ${ }^{1,2}$, Rita-Josiane Gouesse ${ }^{1}$, Nelly Swierkowski-Blanchard ${ }^{3}$, Valérie Serazin ${ }^{1,2}$, Eytan R Barnea ${ }^{4,5}$, \\ François Vialard ${ }^{1,3}$ and Marie-Noëlle Dieudonnék,1
}

From the earliest stages of gestation, embryonic-maternal interaction has a key role in a successful pregnancy. Various factors present during gestation may significantly influence this type of juxta/paracrine interaction. Prelmplantation Factor (PIF) is a recently identified factor with activity at the fetomaternal interface. PIF is secreted by viable embryos and directly controls placental development by increasing the invasive capacity of human extravillous trophoblasts (EVTs). To further specify PIF's role in the human placenta, we analyzed the genome-wide expression profile of the EVT in the presence of a synthetic PIF analog (SPIF). We found that sPIF exposure altered several pathways related to p53 signaling, survival and the immune response. Functional assays revealed that SPIF acts through the p53 pathway to reduce both early and late trophoblast apoptosis. More precisely, sPIF (i) decreases the phosphorylation of p53 at Ser-15, (ii) enhances the B-cell lymphoma-2 (BCL2) expression and (iii) reduces the BCL2associated $X$ protein (BAX) and BCL2 homologous antagonist killer (BAK) mRNA expression levels. Furthermore, invalidation experiments of TP53 allowed us to demonstrate that PIF's effects on placental apoptosis seemed to be essentially mediated by this gene. We have clearly shown that p53 and SPIF pathways could interact in human trophoblast and thus promotes cell survival. Furthermore, sPIF was found to regulate a gene network related to immune tolerance in the EVT, which emphasizes the beneficial effect of this peptide on the human placenta. Finally, the PIF protein levels in placentas from pregnancies affected by preeclampsia or intra-uterine growth restriction were significantly lower than in gestational age-matched control placentas. Taken as a whole, our results suggest that SPIF protects the EVT's functional status through a variety of mechanisms. Clinical application of sPIF in the treatment of disorders of early pregnancy can be envisioned.

Cell Death and Disease (2016) 7, e2504; doi:10.1038/cddis.2016.382; published online 1 December 2016

Placentation is a critical step in the establishment of a successful pregnancy. The placenta is a transitory organ responsible for fetomaternal exchanges and maternal immunotolerance. The chorionic villi constitute the structural and functional units of the placenta. The mature chorionic villus is delimited by a double layer of epithelial cells, the mononuclear villous cytotrophoblast (CTV) and the multinucleate syncytiotrophoblast (ST). ${ }^{1,2}$ The extravillous trophoblast (EVT) has invasive properties that are essential for implantation and uterine artery remodeling. ${ }^{3,4}$ Trophoblast invasion is a highly restricted and regulated process with a pivotal role in the development and progression of pregnancy. However, the molecular mechanisms involved in EVT invasion have not been extensively characterized.

Herein, we focused on preimplantation factor (PIF), a 15-amino-acid peptide (MVRIKPGSANKPSDD) secreted by viable, developing embryos. ${ }^{5,6}$ It is now well established that PIF exerts autotrophic and protective effects on the embryo. ${ }^{7-9}$ Furthermore, PIF is also detected in the maternal circulation throughout pregnancy. The presence of PIF in maternal serum has been correlated with live births in murine and bovine models. ${ }^{10}$ PIF also regulates the maternal environment by promoting human endometrial receptivity. In human decidual cells, PIF exerts pro-apoptotic effects and creates a beneficial pro-inflammatory environment. ${ }^{11,12}$ Moreover, PIF orchestrates maternal systemic immune responses. ${ }^{13}$ Pathway analysis in models of autoimmunity and transplantation have demonstrated that when administered as a single agent to non-pregnant mice, synthetic PIF analog (sPIF) is associated with a reduction in oxidative stress ${ }^{8,14}$ and protein misfolding. ${ }^{15-19}$ Finally, PIF is expressed by the placenta and by hematopoietic fetal tissues. ${ }^{13,20}$ Moindjie et al. have recently reported that PIF expression in trophoblastic cells is prominent in the earliest stages of pregnancy and then declines at term. This observation suggests that endogenous PIF has a significant role in the critical postimplantation phase during which development of the trophoblast must be regulated. Effectively, SPIF was shown to promote invasion in human HTR-8/SVneo trophoblastic cell line. ${ }^{21}$ Recently, we reported that SPIF also increases human EVT invasion without affecting cell proliferation. ${ }^{14,20}$

Coordinated proliferation, differentiation and death of trophoblastic cells are required for the development of a functional placenta. Programmed cell death is an active

\footnotetext{
${ }^{1}$ GIG-EA7404, Université de Versailles Saint-Quentin-en-Yvelines - Paris Saclay, Unité de Formation et de Recherche des Sciences de la Santé-Simone Veil, Montigny-le Bretonneux, France; ${ }^{2}$ Service de Biologie Médicale, Centre Hospitalier de Poissy-Saint Germain, Poissy, France; ${ }^{3}$ Département de Biologie de la Reproduction, Cytogénétique, Gynécologie et Obstétrique, Centre Hospitalier de Poissy-Saint Germain, Poissy, France; ${ }^{4}$ Society for the Investigation of Early Pregnancy, Cherry Hill, NJ, USA and ${ }^{5}$ Biolncept, LLC, Cherry Hill, NJ, USA

*Corresponding author: M-N Dieudonne, EA7404 Gamètes-Implantation-Gestation UFR des Sciences de la SantÃ@) Simone Veil, UniversitÃ@ de Versailles Saint-Quentin-en-Yvelines-Paris Saclay, 2 Avenue de la Source de la Bièvre, Montigny-le Bretonneux F-78180, France. Tel: +33 170 4294 12; Fax: +33 170 4295 06; E-mail: marie-noelle.dieudonne@uvsq.fr

Received 25.3.16; revised 02.9.16; accepted 11.10.16; Edited by Y Haupt
} 


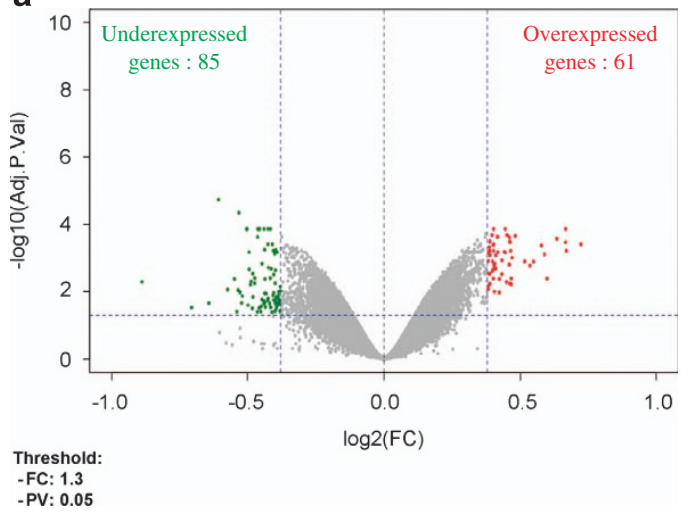

b

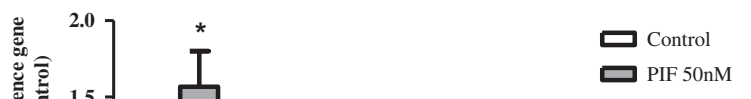

Figure 1 Transcriptomic analysis of the genes differentially regulated by sPIF in EVT. (a) A volcano plot of the FC versus the adjusted $P$-value for the DEGs in EVT cultured in the absence (control) or presence of SPIF $50 \mathrm{nM}$ for $24 \mathrm{~h}$. The two vertical lines correspond to $\mathrm{FC}=1.3$ and the horizontal line corresponds to $P<0.05$. Overexpressed transcripts are shown in red and underexpressed transcripts are shown in green. (b) Quantitative real-time PCR analysis of selected transcripts differentially regulated by sPIF in EVT. EVT were cultured in the absence (control) or presence of sPIF (50 nM) for $24 \mathrm{~h}$. Total RNA was extracted and analyzed by RT-PCR, as described in Materials and Methods section. Values are the mean \pm S.E.M. of six to eight independent experiments and are expressed as fold over control. ${ }^{* \star} P<0.01 ;{ }^{*} P<0.05$. Wilcoxon test. $H B E 1$, hemoglobin epsilon 1; HBG1, hemoglobin gamma 1

process required for normal trophoblastic cell turnover. ${ }^{22-24}$ The tumor-suppressor gene TP53 is a key component in cell cycle progression and the induction of apoptosis. p53 protein is an important transcription factor that regulates growth arrest, apoptosis and DNA repair in response to various stress stimuli. ${ }^{25}$ Upon these cellular stresses, p53 is phosphorylated and acetylated at multiple sites to activate downstream target genes. p53 induces its own negative feedback loop by stimulating the expression of mouse double minute 2 homolog (MDM2), which directly promotes p53 degradation by proteasome. $^{26}$ It is well established that phosphorylation of p53 at Ser-15 leads to the dissociation between MDM2 and p53 and then results to p53 stabilization. ${ }^{25}$ Consequently, Ser-15 phosphorylation contributes to the preferential transactivation of pro-apoptotic genes. ${ }^{27}$ Among its target genes, p53 regulates the expression of the B-cell lymphoma-2 (BCL2) family proteins, which have a crucial role in apoptosis induced through a mitochondria mediated intrinsic pathway. Indeed, p53 stimulates the expression of various cell death inducers, such as BCL2-associated $X$ protein (BAX), and BAK and represses expression of $B C L 2$, a pivotal cell death inhibitor. As BAX and BAK are essential pro-apoptotic mitochondrial proteins responsible for the permeabilization of the mitochondrial outer membrane, an upregulation of BAX and BAK results in the activation of caspase cascade. These modifications result to morphological and biochemical changes associated with apoptosis. ${ }^{28}$ Interestingly, a weak invasiveness and elevated levels of villous trophoblast apoptosis have been described in preeclampsia (PE) ${ }^{29,30}$ and in intra-uterine growth restriction (IUGR). ${ }^{31,32}$

Although detailed studies of the decidua and systemic immunity have already revealed the mechanisms involved in PIF's targeted actions, the molecular mechanisms underlying PIF's effects in human trophoblasts have not been well identified.

In this study, we examined whole-genome gene expression profiles of human primary EVT cultured in the presence or absence of SPIF. Bioinformatic analysis suggested that SPIF has a role in the control of apoptosis and immunity in human trophoblast. By using functional assays, we further demonstrated that SPIF exerts a direct anti-apoptotic effect on human EVT. Finally, we demonstrated that PIF protein levels in the human placental villi from IUGR and PE pregnancies are significantly lower than in gestational age-matched control placentas. These results suggest that the dysregulation of PIF protein expression may be associated with disorders of pregnancy.

\section{Results}

Gene expression profiles in sPIF-treated human EVT. To study the mechanisms possibly affected by treatment with sPIF, we performed a genome-wide microarray analysis of human EVT cultured in the absence (control) or presence of sPIF $(50 \mathrm{nM})$ using an Agilent $8 \times 60 \mathrm{k}$ microarray. This analysis identified groups of genes that were significantly over- or underexpressed (relative to controls) after SPIF treatment of EVT. We opted for an adjusted $P$-value threshold $<0.05$ and a fold-change (FC) cut-off of 1.3. As shown in Figure 1a, sPIF treatment of EVT was associated with significant changes in the expression level of 146 genes (85 downregulated and 61 upregulated). In particular, sPIF upregulated the expression of (i) the gene coding for azurocidin-1 (AZU1), a protein with an important role in the chemotactic and antimicrobial activity of monocytes, (ii) the gene coding for olfactory receptor family 10 subfamily $A$ member 7 (OR10A7), (iii) interleukin 17F (IL17F) and (iv) two long intergenic noncoding RNAs (lincRNAs XLOC-006051 and XLOC-004148). Treatment with SPIF also downregulated the fetal gamma and epsilon globin genes (HBG1 and HBE1, respectively, which are expressed in the yolk sac and turned down after trophoblast differentiation). Gene names, (FC) and adjusted $P$-value for each over- or underexpressed gene are described in Table 1.

To confirm the gene chip data, we used quantitative realtime PCRs to analyze (i) transcripts of the most upregulated 
Table 1 List of the top 20 differentially expressed genes after sPIF treatment of EVTs

\begin{tabular}{|c|c|c|c|}
\hline Symbol & Gene name & Fold-change & $P$-value \\
\hline \multicolumn{4}{|l|}{ Overexpressed genes } \\
\hline LOC100507134 & LOC100507134 (LOC100507134) & 1.652 & 3.804E-04 \\
\hline AZU1 & Azurocidin-1 & 1.592 & $6.085 \mathrm{E}-04$ \\
\hline ENST00000390426 & T cell receptor alpha variable 4 & 1.589 & $1.333 \mathrm{E}-04$ \\
\hline OR10A7 & Olfactory receptor, family 10 , subfamily $A$, member 7 & 1.588 & $3.348 \mathrm{E}-04$ \\
\hline IL17F & Interleukin $17 \mathrm{~F}$ & 1.554 & $2.615 \mathrm{E}-04$ \\
\hline XLOC_006051 & lincRNA & 1.516 & 4.066E-03 \\
\hline XLOC_004148 & lincRNA & 1.505 & 7.676E-04 \\
\hline \multicolumn{4}{|l|}{ Underexpressed genes } \\
\hline HBG1 & Hemoglobin, gamma A & -1.852 & $5.089 \mathrm{E}-03$ \\
\hline HBE1 & Hemoglobin, epsilon 1 & -1.633 & $2.939 \mathrm{E}-02$ \\
\hline RASL10A & RAS-like, family 10 , member $A$ & -1.56 & $2.177 \mathrm{E}-02$ \\
\hline SMOC1 & SPARC-related modular calcium binding 1 & -1.522 & $1.819 \mathrm{E}-05$ \\
\hline HBA2 & Hemoglobin, alpha 2 & -1.487 & 8.713E-03 \\
\hline PRO2852 & Clone FLC0578 PRO2852 mRNA & -1.461 & 4.171E-03 \\
\hline $\mathrm{HBZ}$ & Hemoglobin, zeta & -1.452 & $3.855 \mathrm{E}-02$ \\
\hline VNN2 & Vanin 2 & -1.445 & $4.450 \mathrm{E}-05$ \\
\hline ATG16L2 & ATG16 autophagy-related 16-like 2 & -1.435 & $2.155 \mathrm{E}-02$ \\
\hline FRMD4A & FERM domain-containing $4 \mathrm{~A}$ & -1.432 & $1.335 \mathrm{E}-02$ \\
\hline GRM4 & Glutamate receptor, metabotropic 4 & -1.417 & $1.333 \mathrm{E}-04$ \\
\hline ATP2C2 & ATPase, $\mathrm{Ca}++$ transporting, type $2 \mathrm{C}$, member 2 & -1.412 & 2.492E-02 \\
\hline RPLP2 & Ribosomal protein, large, P2 & -1.408 & $6.604 \mathrm{E}-04$ \\
\hline
\end{tabular}

gene (AZU1) and (ii) transcripts of the two most downregulated genes (HBG1 and HBE1). The expression patterns are correlated with the microarray profiling data (Figure 1b).

Functional networks regulated by SPIF in treated human EVT. First, genes with altered expression in SPIF-treated EVT were analyzed using QIAGEN's Ingenuity Pathway Analysis (IPA) software (Ingenuity Systems, Redwood City, CA, USA). Among the top molecular and cellular functions, 'cancer', 'cellular development, growth and proliferation' and 'cell death and survival, DNA replication, recombination, and repair' functions were identified, with $P$-values of $3.07 \times 10^{-2}$, $3.33 \times 10^{-2}$ and $5.84 \times 10^{-4}$, respectively. Changes in expression after SPIF treatment were observed for 34 genes in the 'cancer' subcategory, 14 genes in the 'cellular development, growth, and proliferation' subcategory and 6 genes in the 'cell death and survival, DNA replication, recombination and repair' subcategory. In the latter gene network shown in Figure 2, sPIF specifically downregulated $B A X, C E C R 2$ (coding for Cat Eye Syndrome Chromosome Region, Candidate 2), INHBA (coding for inhibin beta A) and upregulated BCL2, F7 (coding for coagulation factor VII) and GRN (coding for granulin) in human EVT. All these genes are related to DNA degradation, DNA fragmentation and tumorigenic processes, and three of them are under the control of interferon gamma (IFNG). However, the FC for the IFNG gene $(-1.05)$ was not statistically significant in this experiment.

In order to extract further biological informations, we performed a gene set enrichment analysis (GSEA) of the whole-gene expression data set and found 478 significantly enriched gene sets (false discovery rate (FDR) <0.25). Critical keywords for the gene sets were 'cancer', 'immunity' and 'ion channel transport'. The 'cancer' gene set was downregulated, and the 'immunity' and 'ion channel transport' gene sets were upregulated (data not shown). Differentially expressed genes (DEGs) were analyzed with the Database for Annotation, Visualization, and Integrated Discovery (DAVID). The protein-protein interaction (PPI) relationship was obtained from STRING database, and the PPI network and the functional modules were visualized using Cytoscape (Figure 3). The PPI network contained 424 nodes (representing the DEGs) and 1045 edges (representing the interactions between the DEGs). Next, we used the Kyoto Encyclopedia of Genes and Genomes (KEGG) database to link higher-order biological information to the genomic information associated with these distinct genes and SPIF treatment. The distinct functional categories for the SPIF-associated gene lists are shown in Table 2. Our analysis showed that a few enriched KEGG pathways were related to the 'immune system' and 'viral infection', such as tuberculosis, graft-versus-host disease, type I diabetes mellitus and autoimmune thyroid disease. In confirmation of the gene expression profile data shown in Table 1, sPIF treatment in EVT seems to affect olfactory signal transduction. Finally, the observed expression changes seem to be highly associated with 'tumorigenesis pathways', such as pathways in cancer, apoptosis, and p53 signaling pathway.

Effect of SPIF on human trophoblast viability and apoptosis. To confirm sPIF's effects on apoptosis pathway in human trophoblasts, we performed a number of functional assays. We first used lactate dehydrogenase (LDH) activity and Trypan blue exclusion assays to ascertain viability in EVT and HTR-8/SVneo cells. Our results showed that SPIF (at 50 or $100 \mathrm{nM}$ ) did not affect LDH activity in either cell type (Figure 4a). The Trypan blue exclusion assay confirmed that SPIF did not significantly affect the viability of HTR-8/SVneo cell $(87 \% \pm 1.5,90 \% \pm 1.2$, and $92 \% \pm 0.7$ for the control, $50 \mathrm{nM}$ sPIF and $100 \mathrm{nM}$ sPIF conditions, respectively; $n=4$ 


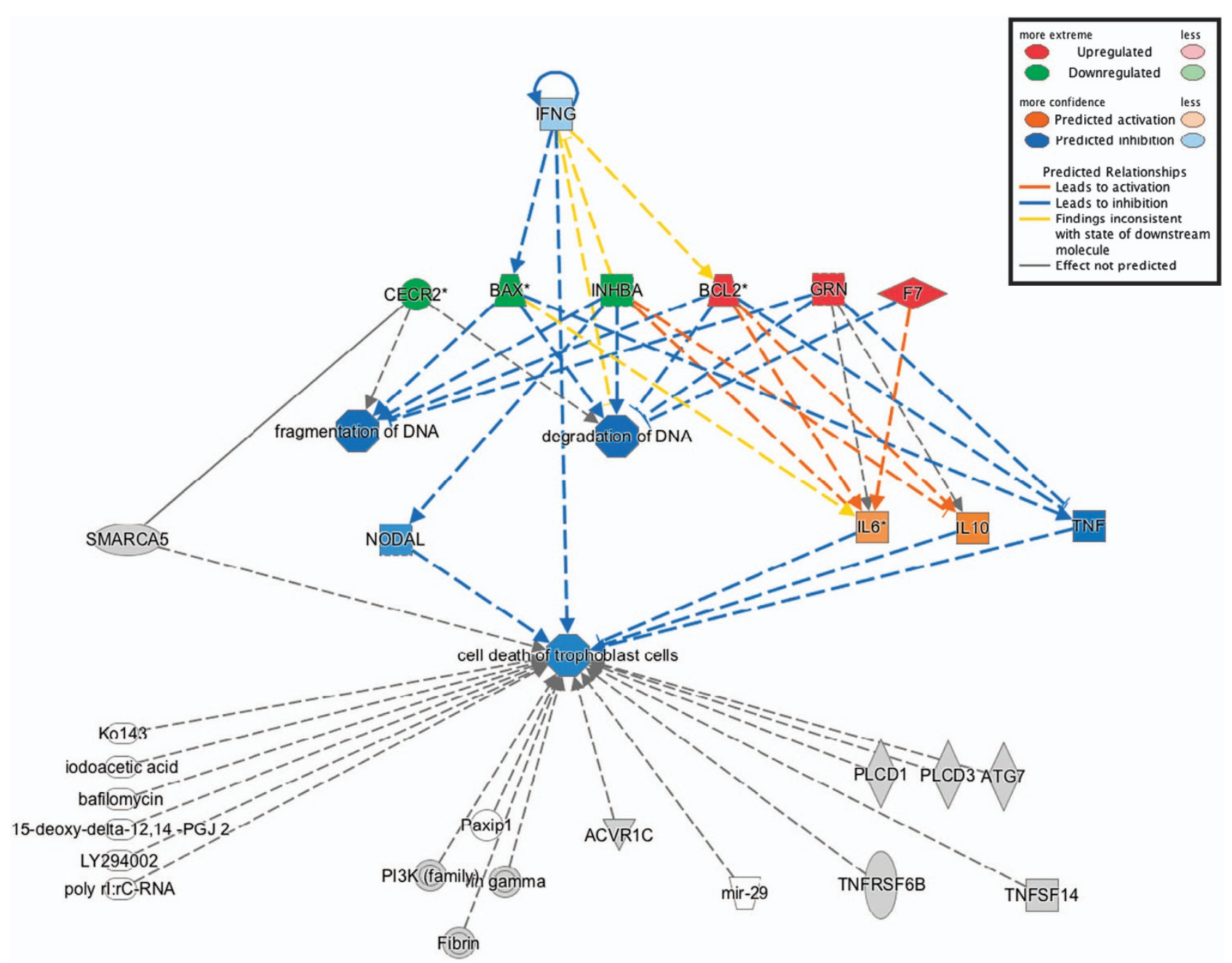

Figure 2 The gene network associated with 'cell death and survival, DNA replication, recombination, and repair' in sPIF-treated EVT. Green shapes present downregulated genes and red shapes present upregulated genes. Predicted relationships are indicated on the figure

for each). Next, we studied the effect of SPIF on the early steps of apoptosis with a flow cytometric annexin V-FITC staining assay. As shown in Figure 4b, exposure of HTR-8/ SVneo cells to SPIF (at 50 and $100 \mathrm{nM}$ ) was associated with lower levels of cell apoptosis (by $26.3 \%$ and $39.6 \%$, respectively). Second, we examined the effects of SPIF on trophoblast DNA fragmentation (the last step of programmed cell death) in a terminal deoxynucleotidyl transferasemediated dUTP-biotin DNA-nick end labeling (TUNEL) assay. As shown in Figure 4c, SPIF (at 50 and $100 \mathrm{nM}$ ) was associated with a significant lower apoptotic index (by $32.2 \%$ and $34.4 \%$, respectively) in HTR-8/SVneo cells.

Effects of sPIF on TP53 mRNA expression, p53 protein levels and p53 activation in human trophoblasts. In order to specify the molecular mechanisms involved in SPIF's antiapoptotic effect, we examined the status of p53 (expression and phosphorylation) in trophoblast cells. First, we measured p53 expression in EVT and HTR-8/SVneo cells. In both cell types, sPIF did not affect TP53 mRNA levels (Figure 5a). p53 protein levels were not modified by treatment with SPIF in
HTR-8/SVneo cells (Figure 5b). The post-translational modification at Ser-15 was shown to be associated with increased p53 stability and transcriptional activity. Then, we have decided to evaluate the effect of SPIF on the Ser-15 phosphorylation state of p53. In the presence of SPIF at 50 and $100 \mathrm{nM}$, the Ser-15 phospho-p53 expression was significantly reduced in HTR-8/SVneo cells (by $24 \%$ and $34 \%$, respectively; Figure 5c). Finally in HTR-8/SVneo cells, we have showed that SPIF treatment decreased the phosphop53 Ser-15/p53 protein ratio (by $35 \%$ at 50 and $100 \mathrm{nM}$; Figure 5d).

Effect of SPIF on p53 transcriptional activity in human trophoblasts. Given that bioinformatics analyses have suggested that SPIF regulated the p53 signaling pathway, we studied the mRNA expression levels of four direct targets of p53 (BCL2, BAX, BAK and MDM2). In EVT, exposure to 50 and $100 \mathrm{nM}$ sPIF resulted in a significant increase of MDM2 (by $35 \%$ and $89 \%$, respectively), and BCL2 gene expression (by $62 \%$ and $64 \%$, respectively). In contrast, sPIF did not affect BAX and BAK gene expression levels under the same 


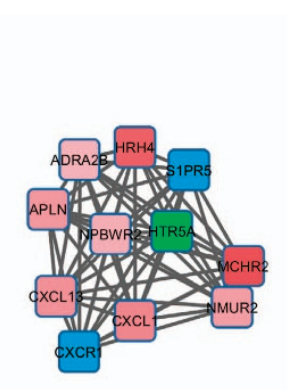

Developmental process
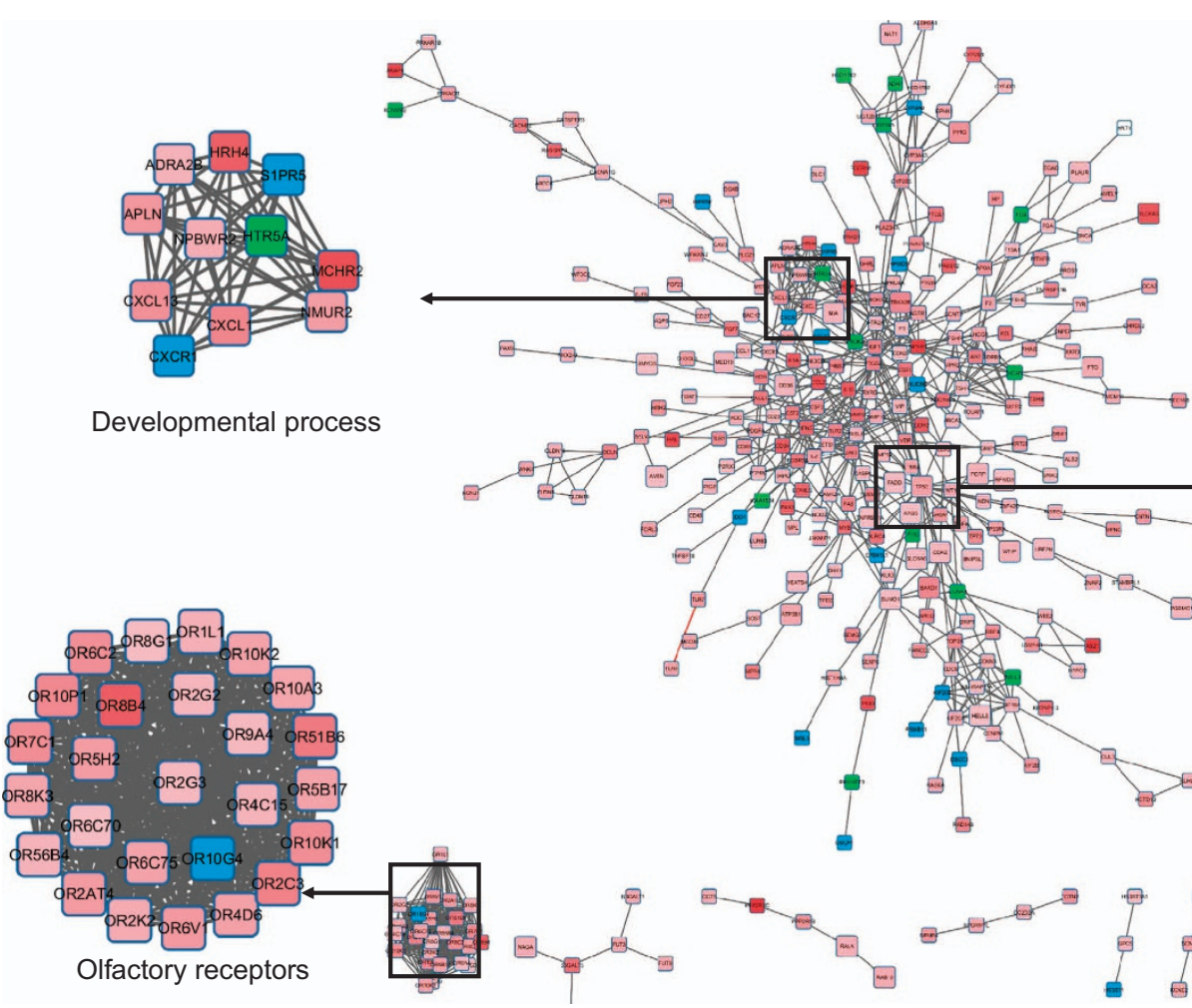

Figure 3 A PPI network analysis. The DEGs identified in the microarray analysis were used to build a PPI network. The STRING database was used to screen interacting proteins, which were then visualized as a PPI network using Cytoscape software. The network nodes represent genes and the edges represented interactions. The size of the nodes is proportional to the number of connections established with other genes. The 'developmental process', 'olfactory receptors' and 'apoptosis' clusters are presented on a larger scale. The gene expression levels were mapped on the network. Red indicates upregulation and green downregulation

experimental conditions, suggesting that these genes are not directly implicated in sPIF anti-apoptotic action in EVT (Figure 6a). As shown in Figure 6b, treatment of HTR-8/ SVneo cells with 50 and $100 \mathrm{nM}$ sPIF was associated with elevated levels of BCL2 mRNA (with relative increases of $26 \%$ and $32 \%$, respectively) and lower of BAX (by $25 \%$ at both doses), and BAK (by $17 \%$ at 50 and $100 \mathrm{nM}$ ) mRNA levels. SPIF treatment was associated with significant decrease of BAX/BCL2 mRNA ratio in both EVT (by 39\% at both doses) and HTR-8/SVneo cells (by $34 \%$ at both doses; Figure 6c). Finally, we have demonstrated that SPIF (at 50 and $100 \mathrm{nM}$ ) increased BCL2 protein level (by $41 \%$ and $148 \%$, respectively) and decreased BAX protein level (by $28 \%$ and $31 \%$, respectively) in HTR-8/SVneo cells (Figure 6d).

To determine whether SPIF anti-apoptotic effect was dependent of $\mathrm{p} 53$, we performed invalidation experiments of p53 in HTR-8/SVneo cells using TP53-specific siRNA (siTP53). We then studied the effect of such knocked down on p53 downstream target gene expression. We observed a significant decrease of TP53 mRNA levels (by $86 \%$ ) confirmed by immunoblot after an invalidation of $48 \mathrm{~h}$ (Figure 7a). When TP53 was downregulated, SPIF-induced increase in the expression of BCL2 and reduce in the expression of BAX were negated (Figures $7 b$ and $c$ ). The PIF's effects on BAX and BCL2 mRNA expression were conserved in presence of siNS. Furthermore, we have shown that SPIF is able to inhibit apoptosis induced by etoposide (by $49 \%$ ), an inhibitory of topoisomerase II, which induce p53 dependent apoptosis. Collectively, these result provide evidence that p53 is required for SPIF-mediated modulation of apoptosis.

PIF protein levels in IUGR and PE placentas. To compare PIF expression levels under normal or pathological conditions, we collected human normal, IUGR and PE placentas. Cytokeratin immunostaining was used as a sensible and reliable marker of trophoblastic cells. As shown in Figure 8A, the PIF protein level was lower in normal third-trimester placentas than in first-trimester villi. Moreover, relative quantification of PIF by immunostaining revealed that PIF protein levels were lower in IUGR and PE placentas than in third-trimester control placentas (Figures $8 \mathrm{a}$ and b).

\section{Discussion}

The trophoblast serves as a vital interphase between embryo and mother, and so effective invasion and survival in the uterus are required. In this respect, it is noteworthy that (i) the trophoblast has a low antigenic imprint and (ii) the uterus displays an adaptive immune system, in order to prevent rejection of the semi-allogenic fetus. Factors that control this delicate balance have been extensively investigated because they may have a significant therapeutic role in difficult pregnancies. ${ }^{33,34}$ Among these factors, PIF is a recently identified peptide with activity at the fetomaternal interface. In 
this context, we performed a genome-wide assessment to better understand the effects of SPIF in the human trophoblast. We tested two different SPIF concentrations (50 and $100 \mathrm{nM}$ ), which correspond to the range observed in the maternal circulation $^{21}$ and where SPIF is effective at modulating trophoblast invasion. ${ }^{20,21}$

Our multifaceted analysis of the signaling involved in sPIF's effect highlighted 'cell survival', 'apoptosis' and 'p53 signaling' pathways, reflecting the presence of robust regulatory control in human trophoblasts.

Our functional experiments effectively demonstrated that SPIF prevents apoptosis in human trophoblasts. More

Table 2 KEGG pathway classification of the top differentially regulated genes after sPIF treatment of EVTs

\begin{tabular}{|c|c|c|}
\hline $\begin{array}{l}\text { KEGG } \\
\text { pathway }\end{array}$ & Pathway name & $P$-value \\
\hline hsa04740 & Olfactory transduction & 3.61E-04 \\
\hline hsa04080 & $\begin{array}{l}\text { Neuroactive ligand-receptor } \\
\text { interaction }\end{array}$ & 9.32E-05 \\
\hline hsa04060 & $\begin{array}{l}\text { Cytokine-cytokine receptor } \\
\text { interaction }\end{array}$ & $7.50 \mathrm{E}-04$ \\
\hline hsa05200 & Pathways in cancer & $5.62 \mathrm{E}-02$ \\
\hline hsa05152 & Tuberculosis & 2.96E-02 \\
\hline hsa05162 & Measles & $6.13 \mathrm{E}-03$ \\
\hline hsa04020 & Calcium signaling pathway & $5.41 \mathrm{E}-02$ \\
\hline hsa05142 & $\begin{array}{l}\text { Chagas disease (American } \\
\text { trypanosomiasis) }\end{array}$ & $1.58 \mathrm{E}-03$ \\
\hline hsa04610 & $\begin{array}{l}\text { Complement and coagulation } \\
\text { cascades }\end{array}$ & $6.48 \mathrm{E}-04$ \\
\hline hsa05146 & Amoebiasis & $1.61 \mathrm{E}-02$ \\
\hline hsa04514 & Cell adhesion molecules (CAMs) & $5.98 \mathrm{E}-02$ \\
\hline hsa04210 & Apoptosis & $1.05 \mathrm{E}-02$ \\
\hline hsa05323 & Rheumatoid arthritis & $1.43 \mathrm{E}-02$ \\
\hline hsa03320 & PPAR signaling pathway & $8.51 \mathrm{E}-03$ \\
\hline hsa04970 & Salivary secretion & $1.95 \mathrm{E}-02$ \\
\hline hsa05332 & Graft-versus-host disease & $5.25 \mathrm{E}-04$ \\
\hline hsa04940 & Type I diabetes mellitus & 8.97E-04 \\
\hline hsa04672 & $\begin{array}{l}\text { Intestinal immune network for IgA } \\
\text { production }\end{array}$ & $2.59 \mathrm{E}-03$ \\
\hline hsa05144 & Malaria & $2.59 \mathrm{E}-03$ \\
\hline hsa00590 & Arachidonic acid metabolism & $9.36 \mathrm{E}-03$ \\
\hline hsa00980 & $\begin{array}{l}\text { Metabolism of xenobiotics by cyto- } \\
\text { chrome P450 }\end{array}$ & $2.10 \mathrm{E}-02$ \\
\hline hsa04971 & Gastric acid secretion & $2.65 \mathrm{E}-02$ \\
\hline hsa05320 & Autoimmune thyroid disease & $1.24 \mathrm{E}-02$ \\
\hline hsa00830 & Retinol metabolism & 2.87E-02 \\
\hline hsa04115 & p53 signaling pathway & 4.86E-02 \\
\hline
\end{tabular}

precisely, in EVT, our results revealed that SPIF exerts its anti-apoptotic effect by upregulating BCL2 without any effect on BAX and BAK mRNA expression levels. In HTR-8/SVneo cells, sPIF upregulates BCL2 and downregulates BAX and BAK expression levels. However, the major finding of this study is a decrease of BAX/BLCL2 mRNA ratio in both cells types. As BCL2 and BAX are direct target genes of p53, we performed p53 invalidation experiments in HTR-8/SVneo cells. Our results revealed that silencing the TP53 gene suppressed sPIF's effect on BAX and BCL2 mRNA expression. These data suggest that sPIF prevents cell death, in part, by regulating the intrinsic apoptotic pathway via p53 in human trophoblastic cells. So, we investigated whether p53 expression and transcriptional activity were regulated by SPIF in these cells. In human EVT, we observed that SPIF induces MDM2 mRNA expression without decrease of p53 expression. This atypical result suggest that SPIF could modulate MDM2 transcription by a p53 independent mechanism. A study realized in rat fibroblasts have effectively shown that fibroblast growth factor 1 directly induces MDM2 mRNA expression without p53 implication. ${ }^{35}$ Furthermore, it is well known that phosphorylation of p53 at certain residues (e.g., at Ser-15) is correlated with an increasing transcriptional activity and consequently with the induction of pro-apoptotic gene expression. ${ }^{36}$ We described that SPIF inhibited the p53 transcriptional activity as suggested by the significant reduction of its phosphorylation status. This last result consolidate the anti-apoptotic role of SPIF in human trophoblasts. It will be interesting to determine the effect of SPIF on the major kinase implicated in the p53 phosphorylation (Ser-15), such as ataxia telangiectasia mutated. ${ }^{37}$ Our results agree with those observed in brain and pancreas, where SPIF has an important role in preventing cell death. ${ }^{16,38,39}$ In particular, it has recently been reported that the PIF-associated inhibition of the death of mouse neuroblastoma cells is associated with an increase in BCL2 expression and a decrease in microRNA let-7 levels. ${ }^{38,39}$ Hence, the sPIF's neuroprotective effect may be due (at least in part) to its ability to inhibit the release of a microRNA that is specifically produced after central nervous system damage. ${ }^{40,41}$ In the field of reproduction, it was recently reported that microRNA let-7 may modulate implantation potential, knockdown of this microRNA in mouse blastocysts completely abolished embryo implantation. ${ }^{42,43}$
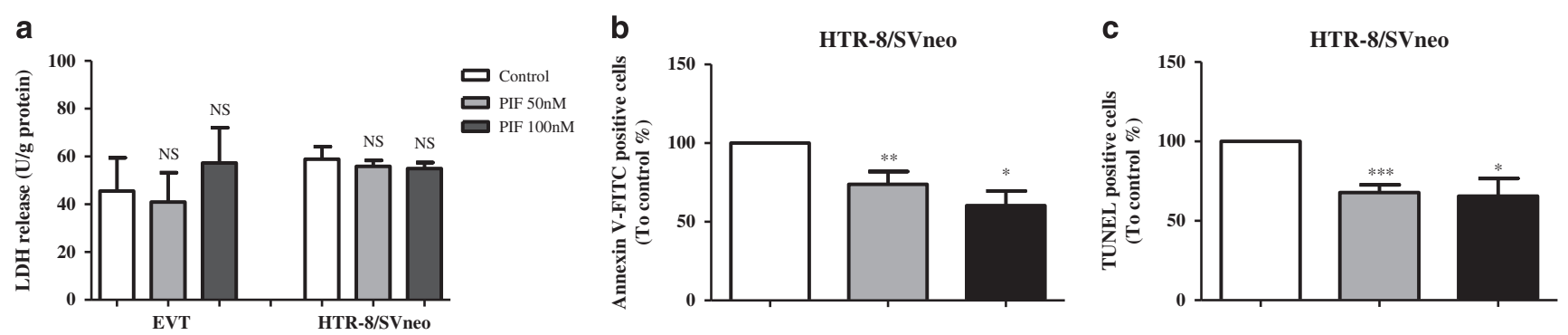

Figure 4 Effect of SPIF on cell viability and apoptosis. (a) LDH levels in the culture medium for human primary EVT and HTR-8/SVneo cells after a 24-h incubation in the absence (control) or presence of SPIF (50 and $100 \mathrm{nM}$ ). The values are the mean \pm S.E.M. of four independent experiments. (b) Annexin V-FITC assay of HTR-8/SVneo cells after $48 \mathrm{~h}$ of culture in the absence (control) or presence of SPIF (50 or $100 \mathrm{nM}$ ). The values are the mean \pm S.E.M. from 10 independent experiments and are expressed as a percentage of the control. (c) TUNEL staining in HTR-8/SVneo cells after $48 \mathrm{~h}$ of culture in the absence (control) or presence of sPIF ( $50 \mathrm{or} 100 \mathrm{nM}$ ). The values are the mean \pm S.E.M. from 6 to 11 independent experiments and are expressed as a percentage of the control. ${ }^{* \star *} P<0.001$; ${ }^{* *} P<0.01 ;{ }^{*} P<0.05$, and NS, nonsignificant. 
a

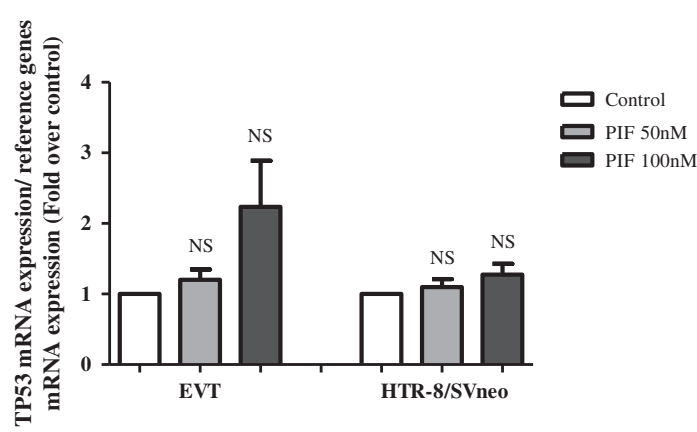

b

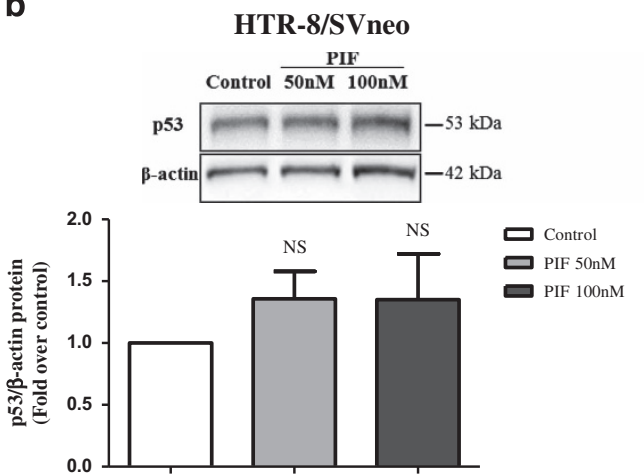

C

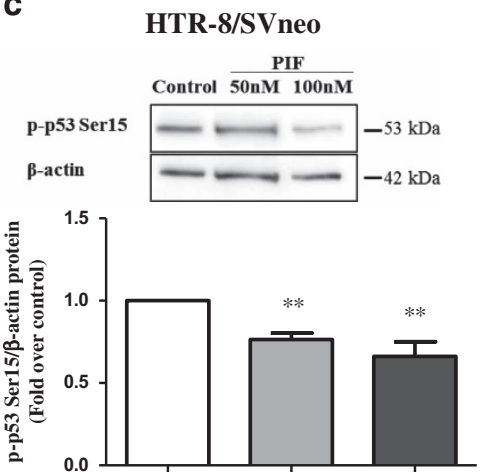

d

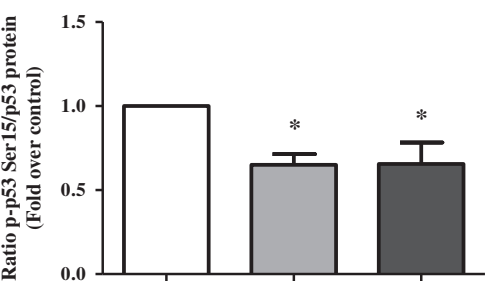

Figure 5 Effect of sPIF on TP53 mRNA expression, p53 protein levels and p53 activation in human trophoblasts. (a) TP53 mRNA expression in trophoblastic cells cultured for $24 \mathrm{~h}$ in the absence (control) or presence of sPIF (50 or $100 \mathrm{nM}$ ). Total RNA was extracted and analyzed by RT-PCR, as described in Materials and methods section. The values are the mean \pm S.E.M. from six to nine independent experiments and are expressed as fold over control. (b) p53 protein expression and (c) phospho-p53 (Ser-15) protein expression were quantified by western blotting, as described in Materials and methods section. (d) The p-p53 Ser-15/p53 protein ratio. Total protein was extracted from HTR-8/ SVneo cells cultured for $24 \mathrm{~h}$ in the absence (control) or presence of SPIF (50 or $100 \mathrm{nM}$ ). The values are the mean \pm S.E.M. from nine independent experiments and are expressed as fold over control. ${ }^{\star *} P<0.01 ;{ }^{*} P<0.05$; NS, nonsignificant. Wilcoxon test
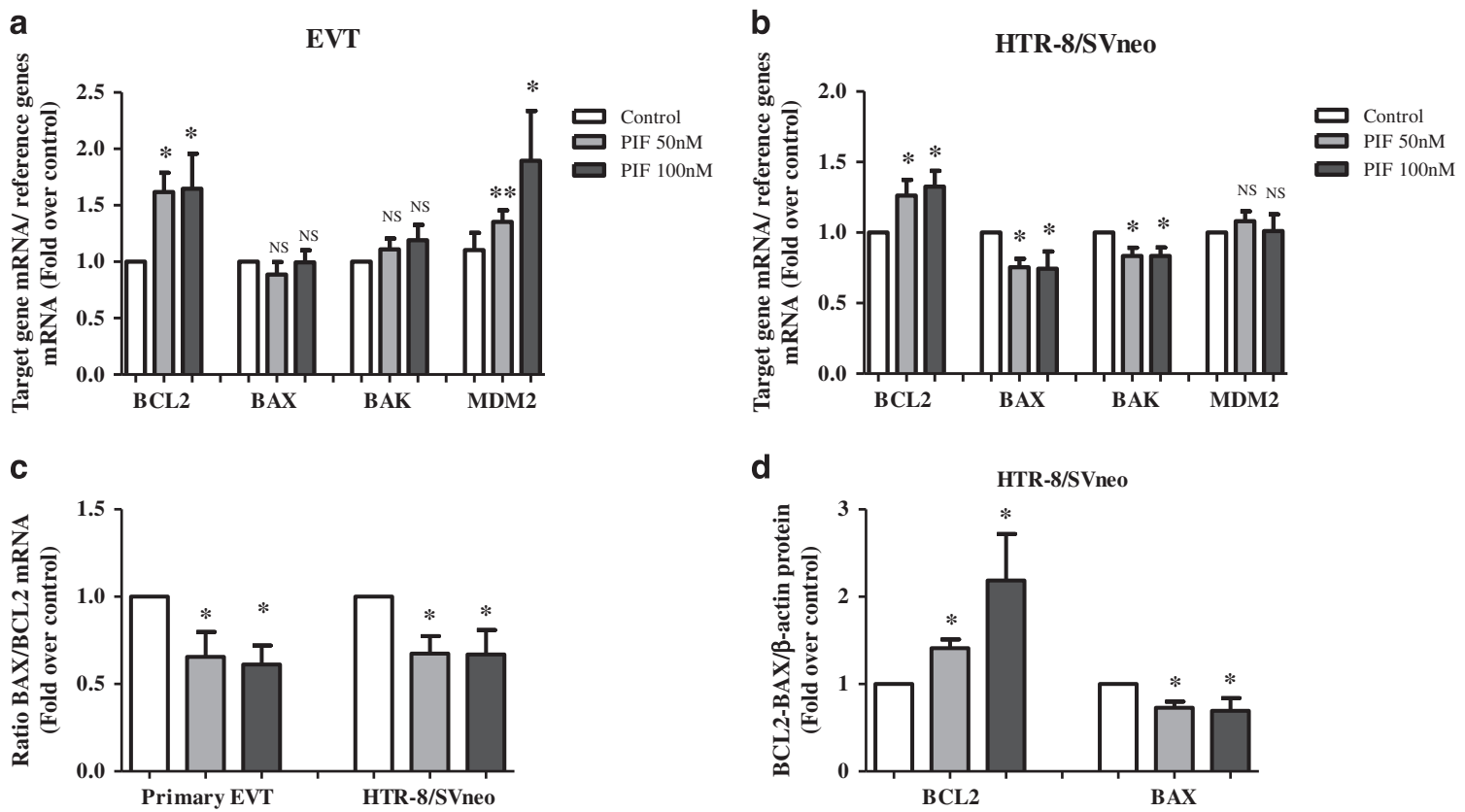

Figure 6 Effect of SPIF on transcriptional targets of p53. BCL2, BAX, BAK and MDM2 mRNA expression levels in (a) primary EVT and (b) HTR-8/SVneo cells after $24 \mathrm{~h}$ of culture in the absence (control) or presence of SPIF (50 or $100 \mathrm{nM}$ ). Total RNA was extracted and analyzed by RT-PCR, as described in Materials and methods section. (c) The BAX/BCL2 mRNA ratio. The values are the mean \pm S.E.M. from six to eight independent experiments and are expressed as fold over control. (d) BCL2 and BAX protein expression levels in HTR-8/SVneo cells were quantified by western blotting, as described in Materials and methods section. The values are the mean \pm S.E.M. from five independent experiments and are expressed as fold over control ${ }^{*} P<0.05$; ${ }^{\star *} P<0.01$; NS, nonsignificant. Wilcoxon test 

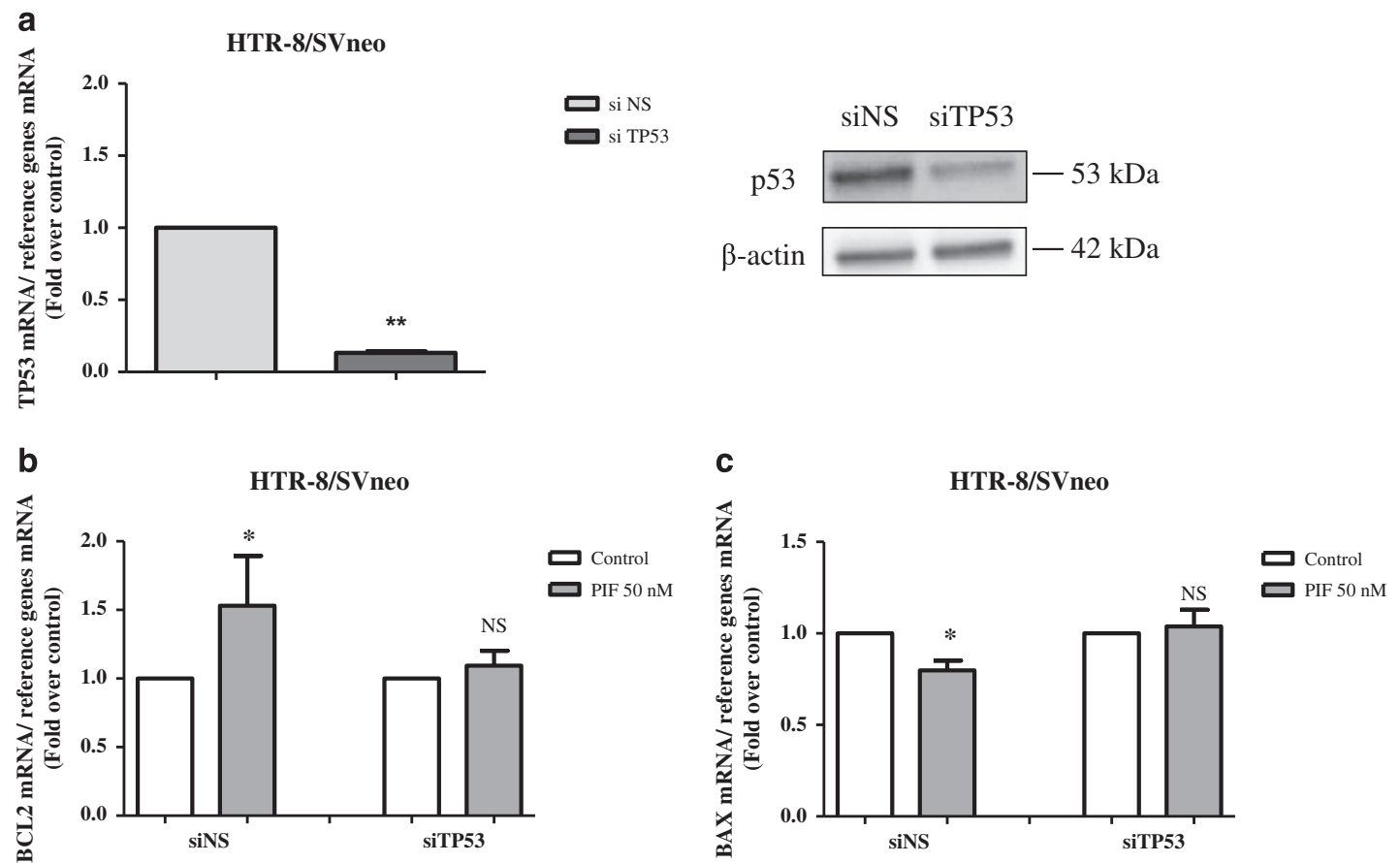

Figure 7 Effect of TP53 silencing in sPIF prevent cell death. HTR-8/SVneo cells were cultured for $48 \mathrm{~h}$ in presence of $10 \mathrm{nM}$ siTP53 or $10 \mathrm{nM}$ siNS. Total mRNA were extracted after treatment and quantified by RT-qPCR as described in Materials and methods section. (a) TP53 mRNA (left panel) and protein (right panel) levels were measured in transfected cells. Results are the mean \pm S.E.M. of six separate experiments. (b and c) HTR-8/SVneo cells transfected with siTP53 or siNS were exposed to sPIF (50 nM). BCL2 (b) and BAX (c) mRNA expression levels were quantified by RT-qPCR. Results are the mean \pm S.E.M. of eight separate experiments. ${ }^{\star} P<0.05 ;{ }^{\star \star} P<0.01$; NS, nonsignificant. Wilcoxon test

a

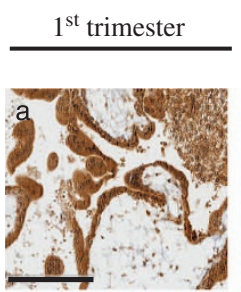

Cytokeratin

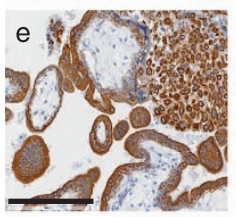

Negative control

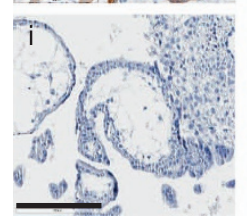

$3^{\text {rd }}$ trimester

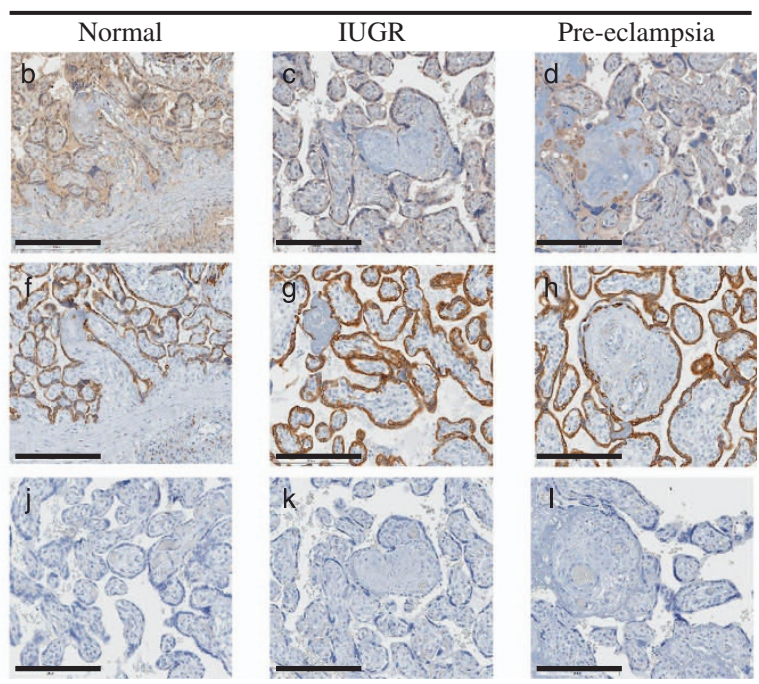

b

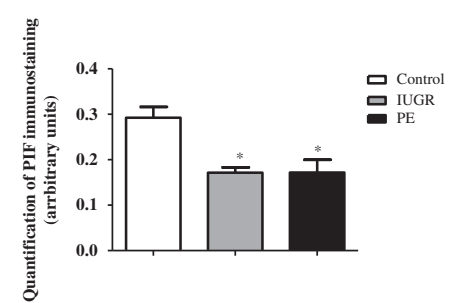

Figure 8 PIF protein levels in human normal, IUGR, and PE placentas. (a) PIF protein immunostaining on sections from first-trimester control ( $n=8)$ (a), third-trimester control $(n=4)(b)$, IUGR $(n=8)$ (c) and PE $(n=4)$ (d) placentas as described in Materials and Methods section. Cytokeratin protein immunostaining was used to identify trophoblastic cells $(e-h)$. The negative control was processed in the absence of primary antibody (i-l). The figure shows one representative among four to eight separate experiments. Magnification, $\times 20$. Scale bar $=200 \mu \mathrm{m}$. (b) Data on the relative quantification of PIF immunostaining are reported as the mean \pm S.E.M. of four to eight independent experiments. ${ }^{*} P<0.05$. Mann-Whitney test

We are currently performing experiments designed to determine microRNA let-7's putative involvement in PIF's actions in human trophoblasts. Consequently, the human placenta provides a novel illustration of sPIF's anti-apoptotic effect.
Conversely, it has been described that SPIF stimulates cell apoptosis in human endometrial cells by suppressing BCL2 expression and inducing downstream effects in the BCL2 network. ${ }^{11}$ It is now well established that effective placenta/ 
endometrium dialog is essential for successful embryo implantation. Hence, sPIF may be involved in paracrine communication by simultaneously exerting anti- and proapoptotic actions on the placenta and the endometrium, respectively. All these data show that SPIF has a crucial, protective role in the establishment and success of pregnancy.

In initial work, we showed that SPIF promotes the invasive phenotype of human EVT isolated from first-trimester placenta. However, cell invasion is a complex, finely spatiotemporally controlled process that is associated with other mechanisms (such as cell proliferation and immune response).

Our gene array analysis revealed the involvement of a 'cancer' gene network in the EVT's response to sPIF. More precisely, SPIF treatment was associated with significantly lower mRNA expression of CECR2 (coding for a transcription factor involved in chromatin remodeling) ${ }^{44}$ and INHBA (coding for a ligand in the transforming growth factor- $\beta$ superfamily). Both gene products are involved in cell cycle progression. By controlling trophoblast proliferation and invasion, sPIF may contribute to the control of normal placental development. We also found that SPIF affects the 'immune response' gene network. Development of tolerance without concomitant immune suppression is essential for effective trophoblast invasion. In this work, the bioinformatics analysis revealed that sPIF induces the mRNA expression of IL17F, a proinflammatory cytokine. It was shown that IL17 upregulates trophoblast invasion. ${ }^{45}$ Hence, sPIF may promote trophoblast invasion by also controlling immune response. PIF's immunoregulatory action is well characterized in various human endometrial, neuronal, pancreatic and blood cell types. ${ }^{11,15,46,47}$ In this study, we found that SPIF strongly induces expression of the $T$ cell receptor alpha variable 4 gene (TRAV4) in EVT. This finding agrees with a previous study of human endometrial cells, in which SPIF was associated with strong (60-fold) induction of the T-cell receptor alpha. ${ }^{11}$ It seems that SPIF exerts the same immune modulatory effects at the fetomaternal interface by favoring immune tolerance, a key factor for successful pregnancy.

Furthermore, our results showed that SPIF modulates the expression of genes related to the 'olfactory gene' network. This finding is not surprising, since earlier studies have already demonstrated that olfactory receptor genes are expressed in tissues other than olfactory epithelium (such as heart, testis and more particularly placenta) suggesting that olfactory receptors may have functions other than odorant recognition. Ikatura et al. ${ }^{48}$ have even suggested that olfactory receptors may be involved in the trophoblastic invasiveness phenotype. Hence, olfactory receptors may be novel factors involved in SPIF's pro-invasive action on human trophoblasts. We are currently performing additional experiments, in order to better define this hypothesis.

Our genome-wide transcriptome analysis also showed that sPIF upregulates lincRNAs. A recent study demonstrated that the lincRNA MALAT-1 regulates proliferation, apoptosis, migration and invasion in trophoblast cells, and that its underexpression may be involved in the pathogenesis of PE. ${ }^{49}$ Hence, sPIF may regulate placental gene expression (and possibly protein function) through this pathway.

Pregnancies affected by IUGR or PE are associated with elevated perinatal mortality and morbidity rates. $P E$ is a multisystem disorder, characterized by hypertension and proteinuria that affects $2-8 \%$ of pregnancies worldwide. ${ }^{50}$ IUGR is characterized by low fetal head circumference, length and weight. ${ }^{51}$ Finally, we found that the level of PIF is relatively lower in the placentas from PE and IUGR as compared with their matched controls. This result suggests that PIF protein levels are disrupted under pathological conditions.

In conclusion, our present results documented a new mechanism for SPIF-mediated trophoblast survival during the first steps in human pregnancy. We also highlighted other sPIF-modulated gene networks related to immune function and tumor suppression that may could complement the PIF's beneficial effects on human placenta. The recognition of sPIF's protective properties by the US Food and Drug Administration has enabled fast-track approval of clinical trials in the treatment of autoimmune hepatitis in non-pregnant subjects. Hence, the use of SPIF could be envisaged in the prevention or treatment of disorders of early pregnancy associated with impaired placentation. ${ }^{14}$

\section{Materials and Methods}

Materials. SPIF analog (purity $>95 \%$, as documented by HPLC and mass spectrometry) was produced by Biosynthesis (Lewisville, TX, USA). DMEM-Ham's Nutrient Mix F12 (DMEM/F12), RPMl-1640 medium, penicillin-streptomycin mix, HEPES, $\mathrm{MgSO}_{4}$, dimethyl sulfoxide, bovine serum albumin (BSA), Percoll, rabbit monoclonal anti- $\beta$-actin and DNase type IV were purchased from Sigma Chemical Co. (St. Louis, MO, USA). Matrigel was obtained from BD Biosciences (Le Pont-deClaix, France) and trypsin was purchased from Difco Laboratories (Detroit, MI, USA). Hank's balanced salt solution and fetal calf serum (FCS) were purchased from Gibco (Invitrogen, Carlsbad, CA, USA). Superscript II RNase H-RT and primers were purchased from Invitrogen and RNAse inhibitor was obtained from AMRESCO (Solon, OH, USA). The Nucleospin RNA kit was obtained from Macherey-Nagel (Düren, Germany). The annexin V-FITC reagent was obtained from Abcam (Cambridge, UK). Precise Tris-glycine gels 4-20\% and SuperSignal ${ }^{\mathrm{TM}}$ West Pico Chemiluminescent Substrate were obtained from Thermo Fisher Scientific Inc. (Waltham, MA, USA). Mouse monoclonal anti-cytokeratin, pan antibody (KL1) was purchased from Dako (Trappes, France), mouse monoclonal anti-PIF antibody was produced by GenWay (San Diego, CA, USA), rabbit polyclonal anti-phospho-p53 (Ser-15) was purchased from Cell Signaling Technology (Beverly, MA, USA) and mouse monoclonal anti-p53 (DO-1) was purchased from Santa Cruz Biotechnologies Inc. (Santa Cruz, CA, USA). The DAB (3, 3'-diaminobenzidine) detection kit was obtained from Ventana Medical Systems (Tucson, AZ, USA). p53 small-interfering RNA (sip53) were chemically synthesized by Santa Cruz Biotechnologies Inc.

Tissue collection. First-trimester human placentas were obtained from legal, elective abortions, after 4-12 weeks of gestation (WG), following the provision of written, informed consent. Third-trimester placentas were collected after elective cesarean section. The indications for cesarean section were not related to fetal growth status. The main inclusion criterion for IUGR group was a birth weight below the 10th percentile for gestational age (using growth charts for the French population). PE was defined as the onset of maternal hypertension and proteinuria after 20 week's gestation (systolic blood pressure $\geq 140 \mathrm{~mm} \mathrm{Hg}$; diastolic blood pressure $\geq 90 \mathrm{~mm} \mathrm{Hg}$; proteinuria $\geq 300 \mathrm{mg}$ per $24 \mathrm{~h}$ ). This and all other study procedures had been approved by the local investigational review board (Comité Consultatif de Protection des Personnes dans la Recherche Médicale reference: 01-78). Four- to 7-WG placental tissues were obtained after pharmaceutical abortion and 8- to 12-WG placental tissues were obtained after surgical abortion.

Cell culture. Primary EVT were isolated using an adaptation of the method previously described by Handschuh et al., ${ }^{52}$ and as reported elsewhere. ${ }^{20}$ EVT were seeded onto $5 \mathrm{mg} / \mathrm{ml}$ Matrigel-coated dishes containing DMEM/F12 with $1 \%$ FCS, penicillin $(100 \mathrm{U} / \mathrm{ml})$ and streptomycin $(100 \mu \mathrm{g} / \mathrm{ml})$. The human EVT cell line HTR-8/ SVneo, derived from the invasive EVT, was kindly provided by Dr. Nadia Alfaidy (CEA Grenoble, France), in agreement with Dr. Charles Graham (Queen's 
Table 3 Primers used for PCR

\begin{tabular}{|c|c|c|}
\hline Primer set & Sequence & $\begin{array}{l}\text { PCR } \\
\text { product } \\
(\mathrm{pb})\end{array}$ \\
\hline \multicolumn{3}{|l|}{$A Z U 1$} \\
\hline $\begin{array}{l}\text { Sense } \\
\text { Antisense }\end{array}$ & $\begin{array}{l}\text { 5'-CCCCTTTTGGACATCGTTGG-3' } \\
\text { 3'-CCCGGGGTTCTGGCTTTG-5' }\end{array}$ & 159 \\
\hline \multicolumn{3}{|l|}{ HBG1 } \\
\hline $\begin{array}{l}\text { Sense } \\
\text { Antisense }\end{array}$ & $\begin{array}{l}\text { 5'-CACTCGCTTCTGGAACGTCT-3' } \\
\text { 3'-GGTAGACAACCAGGAGCCTTC-5' }\end{array}$ & 161 \\
\hline \multicolumn{3}{|l|}{ HBE1 } \\
\hline $\begin{array}{l}\text { Sense } \\
\text { Antisense }\end{array}$ & $\begin{array}{l}\text { 5'-CTTCAAGCTCCTGGGTAACG-3' } \\
\text { 3'-GTCAGGGTCACAGGAACACC-5' }\end{array}$ & 174 \\
\hline \multicolumn{3}{|l|}{ TP53 } \\
\hline $\begin{array}{l}\text { Sense } \\
\text { Antisense }\end{array}$ & $\begin{array}{l}\text { 5'-ACTAAGCGAGCACTGCCCAA-3' } \\
\text { 3'-CAGTCAGATGGAGGGCGGTA-5' }\end{array}$ & 231 \\
\hline \multicolumn{3}{|l|}{$B C L-2$} \\
\hline $\begin{array}{l}\text { Sense } \\
\text { Antisense }\end{array}$ & $\begin{array}{l}\text { 5'-ATGTGTGTGGAGAGCGTCAACC-3' } \\
\text { 3'-CCGACAGAGTCATCTGAGGCATGA-5' }\end{array}$ & 196 \\
\hline \multicolumn{3}{|l|}{$B A X$} \\
\hline $\begin{array}{l}\text { Sense } \\
\text { Antisense }\end{array}$ & $\begin{array}{l}\text { 5'-CAAACTGGTGCTCAAGGCC-3' } \\
\text { 3'-TAGAAACACCGCCCTCACG-5' }\end{array}$ & 188 \\
\hline \multicolumn{3}{|l|}{$B A K$} \\
\hline $\begin{array}{l}\text { Sense } \\
\text { Antisense }\end{array}$ & $\begin{array}{l}\text { 5'-CCATTCCTGGAAACTGGGCT-3' } \\
\text { 3'-CCGTCCGACTAGGGCAG-5' }\end{array}$ & 125 \\
\hline \multicolumn{3}{|l|}{ MDM2 } \\
\hline $\begin{array}{l}\text { Sense } \\
\text { Antisense }\end{array}$ & $\begin{array}{l}\text { 5'-GTGAAGGAAACTGGGGAGTCTT-3' } \\
\text { 3'-ACGTTATGGTTTTACAGACATGGA-5' }\end{array}$ & 101 \\
\hline \multicolumn{3}{|l|}{ TBP } \\
\hline $\begin{array}{l}\text { Sense } \\
\text { Antisense }\end{array}$ & $\begin{array}{l}\text { 5'-TGCACAGGAGCCAAGAGTGAA-3' } \\
\text { 3'-CACATCACAGCTCCCCACCA-5' }\end{array}$ & 132 \\
\hline \multicolumn{3}{|c|}{$\begin{array}{l}\text { B2- } \\
\text { MICROGLOBULIN }\end{array}$} \\
\hline $\begin{array}{l}\text { Sense } \\
\text { Antisense }\end{array}$ & $\begin{array}{l}\text { 5'-TGCTGTCTCCATGTTTGATGTATCT-3' } \\
\text { 3'-TCTCTGCTCCCCACCTCTAAGT-5' }\end{array}$ & 86 \\
\hline \multicolumn{3}{|l|}{$R P L 13 A$} \\
\hline $\begin{array}{l}\text { Sense } \\
\text { Antisense }\end{array}$ & $\begin{array}{l}\text { 5'-CCTGGAGGAGAAGAGGAAAGAGA-3' } \\
\text { 3'-TTGAGGACCTCTGTGTATTTGTCAA-5' }\end{array}$ & 125 \\
\hline
\end{tabular}

University, Kingston, ON, Canada). Cells were grown in RPMl-1640 medium with $2 \%$ HEPES, penicillin $(100 \mathrm{U} / \mathrm{ml})$, streptomycin $(100 \mu \mathrm{g} / \mathrm{ml})$ and $10 \% \mathrm{FCS}$.

Treatment of cultured cells. HTR-8/SVneo cells were cultured in serumfree RPMI-1640 medium for $24 \mathrm{~h}$. EVT were cultured in serum-free DMEM/F12 for $24 \mathrm{~h}$. The next day, media were removed and replaced by serum-free media supplemented with SPIF (50 or $100 \mathrm{nM})$ or etoposide $(42 \mu \mathrm{M})$.

Microarray assays. EVT were cultured in the absence (control) or presence of sPIF (50 nM) for $24 \mathrm{~h}$. Then, total RNA was extracted using the Nucleospin RNA kit's instructions. RNA integrity and purity were checked using a 2100 Bioanalyzer (Agilent Technologies, Massy, France). Four sets of experiments were collected and the expression profile was analyzed with an Agilent ${ }^{\circledR}$ SurePrint G3 Human GE $8 \times 60 \mathrm{~K}$ Microarray (Agilent Technologies, AMADID 039494) using the following dual-color design: SPIF-treated samples were labeled with Cy5 and control samples were labeled with Cy3, using a two-color labeling kit (Low Input Quick Amp Labeling Kit 5190-2306, Agilent Technologies) adapted for small amounts of total RNA (100 ng total RNA per reaction). Hybridization on the microarray was then performed with $825 \mathrm{ng}$ of each linearly amplified and then Cy3- or Cy5-labeled CRNA sample, according to the manufacturer's instructions (Agilent SureHyb Chamber; $1650 \mathrm{ng}$ of labeled extract; $17 \mathrm{~h}$ of hybridization; $40 \mu \mathrm{l}$ per array; $65^{\circ} \mathrm{C}$ ). After washing in acetonitrile, slides were scanned with an Agilent G2565 C DNA microarray scanner, using the latter's default parameters. Microarray images were analyzed with Feature Extraction software (version 10.7.3.1, Agilent Technologies). Again, the default settings were used.

Microarray data processing and analysis. Raw data files from Feature Extraction were imported into $R$ using LIMMA ${ }^{53}$ and a $R$ package from the Bioconductor project, and processed as follow: gMedianSignal and rMedianSignal data were imported, control probes were systematically removed, and flagged probes (glsSaturated, glsFeatpopnOL, glsFeatNonUnifOL, rlsSaturated, rlsFeatpopnOL and rlsFeatNonUnifOL) were set to 'NA'. Intra-array normalization was performed by 'loess' normalization, followed by quantile normalization of both the Cy3 and Cy5 channels. Next, inter-array difference was normalized by quantile normalization on $\mathrm{M}$ values. All probes were then summarized into single genes by taking the mean of all probes that corresponds to the same gene. The missing values were eventually replaced using the KNN algorithm.

Bioinformatics analysis was completed by applying ArrayMining software (http:// www.arraymining.net) and the Cytoscape package. The transcriptome analysis for microarrays was carried out using complementary approaches: a DAVID analysis of the most deregulated genes and a GSEA analysis of enriched pathways $(F D R<0.25)$. The Search Tool for the Retrieval of Interacting Genes (STRING: $\mathrm{http}: / /$ string-db.org/ $)^{54}$ was used to screen DEGs for pairs of interacting protein pairs, which were then visualized within the PPI network using Cytoscape (http://cytoscape. org/)..$^{55}$ After identifying the DEGs, gene ontology enrichment and KEGG pathway analyses ${ }^{56,57}$ were performed. The KEGG pathways with $P$-value below 0.05 were selected as enriched functions for the DEGs.

Quantitative RT-PCR. Total RNA $(0.1 \mu \mathrm{g})$ was extracted and reversetranscribed, as previously described. ${ }^{58}$ Quantitative RT-PCR was performed with the primer sets indicated in Table 3 and DyNAmo Flash SYBR green qPCR (Thermo Fisher Scientific Inc.), using a CFX $96^{\mathrm{TM}}$ real-time PCR detection instrument (Bio-Rad Laboratories Inc., USA). The second derivative maximum method was used to automatically determine the crossing point $(\mathrm{CP})$ for individual samples. Three reference genes (ribosomal protein L13A (RPL13A), TATA box binding protein (TBP) and $\beta$-2 microglobulin (B2M)) were chosen, as previously described. ${ }^{59}$ For each sample, the concentration ratio (target versus three reference mRNAs) were calculated using CFX Manager (Version 3.0, Bio-Rad, Munich, Germany) and expressed in arbitrary units. Calibration curves were log-linear over the quantification range, with correlation coefficients $\left(r^{2}\right)>0.99$ and efficiencies ranging from 1.8 to 2 . The PCR products were separated on a $2 \%$ agarose gel in $90 \mathrm{mM}$ Tris-borate, $2 \mathrm{mM}$ EDTA buffer $\mathrm{pH}$ 8.0, and visualized using GelRed nucleic acid staining and ultraviolet transillumination.

Cell viability assay. Cell viability was determined in a Trypan blue dye exclusion assay. ${ }^{60}$ Following SPIF treatment, HTR-8/SVneo cells were harvested by trypsinization and incubated for 5 min with $0.04 \%$ Trypan blue solution at room temperature. Blue cells (non-viable) versus white cells (viable) were counted in a hemocytometer. Cell viability was determined by normalizing the number of white cells against the total number of cells. In parallel, LDH activity ${ }^{61}$ released into the culture media was assayed, as previously described. ${ }^{62}$ The results were expressed per $g$ of total proteins. Protein concentrations were measured according to Bradford's method ${ }^{63}$ using BSA as a standard.

Annexin V-FITC assay. HTR-8/SVneo cells $\left(1 \times 10^{6}\right.$ cells per well) were plated onto 6-well culture plates. After $48 \mathrm{~h}$ of sPIF treatment, cells were stained using an apoptosis detection kit (Abcam), according to the manufacturer's instructions. Flow cytometry analysis of annexin V-FITC staining was performed using an imaging flow cytometer (Amnis/EMD, Imagestream, Merck-Millipore, Darmstadt, Germany). A total of 1000 events were acquired at $\times 40$ magnification, and annexin V-positive cells were quantified using IDEAS 5.0 software (Amnis/EMD, Darmstadt, Germany). Bright field images were used to quantify and verify cell integrity. The apoptosis rate was determined by normalizing annexin V-positive cells against the total number of cells. Etoposide $(42 \mu \mathrm{M})$ was used as positive control (data not shown).

TUNEL assay. HTR-8/SVneo cells were cultured at a density of $2 \times 10^{5}$ cells per well in 12-well culture plates. After $48 \mathrm{~h}$ of sPIF treatment, cells were fixed in $4 \%$ paraformaldehyde for $20 \mathrm{~min}$ at room temperature, washed, and stained using a TUNEL apoptosis kit (In Situ Cell Death Detection Kit, Fluorescein, Roche Diagnostics $\mathrm{GmbH}$, Mannheim, Germany) according to the manufacturer's instructions. Cells were counterstained with $1 \mu \mathrm{g} / \mathrm{ml}$ Hoechst33258 (Sigma, St. Louis, MO, USA). Ten fields in each well were imaged using an inverted fluorescence microscope (Olympus, ScanR, Tokyo, Japan), in order to obtain a minimum of 200 cells for analysis. The apoptosis rate was determined by normalizing the number of TUNEL-positive cells against the total number of Hoechst-positive cells, using ScanR software (Olympus, ScanR). Etoposide (42 $\mu \mathrm{M})$ was used as positive control (data not shown). 
Immunoblotting. HTR-8/SVneo cells $\left(1 \times 10^{6}\right.$ cells per well) were plated onto six-well culture plates. After $48 \mathrm{~h}$ of SPIF treatment, cells were lysed in extraction buffer, as previously described. ${ }^{64}$ Twenty micrograms of total protein was resolved by SDS-PAGE (4-20\% acrylamide) and transferred onto nitrocellulose membranes using a wet transfer method. After protein transfer, membranes were incubated at $4{ }^{\circ} \mathrm{C}$ overnight with rabbit polyclonal anti-phospho-p53 (Ser-15, 1: 500 dilution, Cell Signaling Technology), mouse monoclonal anti-p53 (DO-1, 1 : 1000 dilution, Santa Cruz Biotechnologies, Inc.), anti-BCL2 (sc-509, 1:200 dilution, Santa Cruz Biotechnologies, Inc.), anti-BAX (sc-493, 1:200 dilution, Santa Cruz Biotechnologies, Inc.) or rabbit monoclonal anti $\beta$-actin (1:500 dilution, Sigma). After washing, the membranes were incubated with the peroxidase-coupled secondary antibody for $1 \mathrm{~h}$ at room temperature. Blots were developed using the SuperSignal ${ }^{\mathrm{TM}}$ West Pico Chemiluminescent Substrate (Thermo Fisher Scientific Inc.)

TP53 siRNA knockdown. The siRNA for TP53 (p53 siRNA (h): sc29431) was purchased from Santa Cruz Biotechnologies Inc. A fluorescently labeled, nonsilencing control siRNA was useful for the optimization of transfection conditions and as a control for nonspecific silencing effects. For the knockdown experiments, HTR-8/SVneo cells were plated in 12-well dishes at $1 \times 10^{5}$ cells per well. Cells were transfected with siRNAs (10 nM per well) using a Lipofectamine RNAiMAX transfection reagent from Invitrogen according to the manufacturer's instructions. sPIF (50) was added $24 \mathrm{~h}$ after transfection. After $48 \mathrm{~h}$ of culture, the mRNA expression was analyzed by RT-qPCR as described above.

Immunohistochemistry. Sixteen placental samples (four controls, eight IUGR samples and four PE samples) were processed as previously described. ${ }^{20}$ Digital images of dimethylaminoazobenzene-stained placenta slides were obtained at $\times 20$ magnification using a whole slide scanner (Aperio AT2, Leica Biosystems, Nusslosh, Germany). Specific immunostaining in three representative fields was quantified using the positive pixel count algorithm in Aperio Imagescope software (Leica Biosystems)

Statistical analysis. Results were analyzed using Graphpad Prism software (version 5.0, GraphPad Software, Inc., La Jolla, CA, USA) and expressed as the mean \pm S.E.M. of 4-11 separate experiments. Statistical analyses were performed using a non-parametric, paired Wilcoxon's test or a non-parametric Mann-Whitney test. The statistics for assessing the enrichment of group of genes is always based on $\mathrm{Chi}^{2}$ contingency tests that are directly performed online by DAVID, STRING or Cytoscape tools. The threshold for statistical significance was set to $P<0.05$.

\section{Conflict of Interest}

The authors declare no conflict of interest.

Acknowledgements. This work was funded in part by a Grant for Fertility Innovation from Merck Serono (Darmstadt, Germany) and by the Université de Versailles Saint-Quentin-en-Yvelines (Versailles, France). Biolncept (Cherry Hill, NJ, USA) supplied the SPIF reagent. The microarray data processing and analysis was performed on Plateforme de Génomique Fonctionnelle of Gustave Roussy Institut. We thank Dr. Daniel Vaiman for his help with the bioinformatics analysis. TUNEL and Annexin V-FITC image acquisition and analysis were performed on CYMAGES platform. Immunoperoxidase image acquisition and analysis were performed on immunohistochemistry platform, both supported by the community of Saint-Quentinen-Yvelines and the University of Versailles Saint-Quentin. We thank Caroline Pirou, Fabien Duval and Laurent Ruiz for their technical help.

1. Evain-Brion D. The 2 differentiation pathways of the human trophoblast. Gynécologie Obstétrique Fertil 2001; 29: 497-502.

2. Staun-Ram E, Shalev E. Human trophoblast function during the implantation process Reprod Biol Endocrinol 2005; 3: 56

3. Knofler M, Simmons DG, Lash GE, Harris LK, Armant DR. Regulation of trophoblast invasion a workshop report. Placenta 2008; 29: S26-S28.

4. Lunghi L, Ferretti ME, Medici S, Biondi C, Vesce F. Control of human trophoblast function. Reprod Biol Endocrinol 2007; 5: 6.

5. Stamatkin CW, Roussev RG, Stout M, Absalon-Medina V, Ramu S, Goodman C et al. Preimplantation factor (PIF) correlates with early mammalian embryo development-bovine and murine models. Reprod Biol Endocrinol 2011; 9: 63.
6. Roussev RG, Coulam CB, Kaider BD, Yarkoni M, Leavis PC, Barnea ER. Embryonic origin of preimplantation factor (PIF): biological activity and partial characterization. Mol Hum Reprod 1996; 2: 883-887.

7. Duzyj CM, Paidas MJ, Jebailey L, Huang JS, Barnea ER. Preimplantation factor $\left(\mathrm{PIF}^{\star}\right)$ promotes embryotrophic and neuroprotective decidual genes: effect negated by epidermal growth factor. J Neurodev Disord 2014; 6: 36

8. Barnea ER, Lubman DM, Liu Y-H, Absalon-Medina V, Hayrabedyan S, Todorova K et al. Insight into preimplantation factor ( $\mathrm{PIF}^{*}$ ) mechanism for embryo protection and development target oxidative stress and protein misfolding (PDI and HSP) through essential RIPK binding site. PloS One 2014; 9: e100263.

9. Stamatkin CW, Roussev RG, Stout M, Coulam CB, Triche E, Godke RA et al. Preimplantation factor negates embryo toxicity and promotes embryo development in culture. Reprod Biomed Online 2011; 23: 517-524.

10. Ramu S, Stamatkin C, Timms L, Ruble M, Roussev RG, Barnea ER. Prelmplantation factor (PIF) detection in maternal circulation in early pregnancy correlates with live birth (bovine model). Reprod Biol Endocrinol 2013; 11: 105.

11. Paidas MJ, Krikun G, Huang SJ, Jones R, Romano M, Annunziato J et al. A genomic and proteomic investigation of the impact of preimplantation factor on human decidual cells. Am J Obstet Gynecol 2010; 202: 459.e1-e8.

12. Barnea ER, Kirk D, Paidas MJ. Prelmplantation factor (PIF) promoting role in embryo implantation: increases endometrial Integrin- $\alpha 2 \beta 3$, amphiregulin and epiregulin while reducing betacellulin expression via MAPK in decidua. Reprod Biol Endocrinol 2012; 10: 50.

13. Barnea ER. Applying embryo-derived immune tolerance to the treatment of immune disorders. Ann N Y Acad Sci 2007; 1110: 602-618.

14. Barnea ER, Vialard F, Moindjie H, Ornaghi S, Dieudonne MN, Paidas MJ. Preimplantation factor $\left(\mathrm{PIF}^{*}\right)$ endogenously prevents preeclampsia: promotes trophoblast invasion and reduces oxidative stress. J Reprod Immunol 2016; 114: 58-64.

15. Weiss L, Bernstein S, Jones R, Amunugama R, Krizman D, Jebailey L et al. Preimplantation factor (PIF) analog prevents type I diabetes mellitus (TIDM) development by preserving pancreatic function in NOD mice. Endocrine 2011; 40: 41-54.

16. Weiss L, Or R, Jones RC, Amunugama R, JeBailey L, Ramu $S$ et al. Preimplantation factor (PIF*) reverses neuroinflammation while promoting neural repair in EAE model. J Neurol SCi 2012; 312: 146-157.

17. Paidas MJ, Annunziato J, Romano M, Weiss L, Or R, Barnea ER. Pregnancy and multiple sclerosis (MS): a beneficial association. Possible therapeutic application of embryo-specific pre-implantation factor (PIF*). Am J Reprod Immunol N Y N 1989 2012; 68: 456-464.

18. Azar Y, Shainer R, Almogi-Hazan O, Bringer R, Compton SR, Paidas MJ et al. Preimplantation factor reduces graft-versus-host disease by regulating immune response and lowering oxidative stress (murine model). Biol Blood Marrow Transplant J Am Soc Blood Marrow Transplant 2013; 19: 519-528.

19. Shainer R, Azar Y, Almogi-Hazan O, Bringer R, Compton SR, Paidas MJ et al. Immune regulation and oxidative stress reduction by preimplantation factor following syngeneic or allogeneic bone marrow transplantation. Conf Pap Med 2013; 2013: 1-8.

20. Moindjie H, Santos ED, Loeuillet L, Gronier H, de Mazancourt P, Barnea ER et al. Preimplantation factor (PIF) promotes human trophoblast invasion. Biol Reprod 2014; 91: 118

21. Duzyj CM, Barnea ER, Li M, Huang SJ, Krikun G, Paidas MJ. Preimplantation factor promotes first trimester trophoblast invasion. Am J Obstet Gynecol 2010; 203: 402.e1-e4.

22. Longtine MS, Chen B, Odibo AO, Zhong Y, Nelson DM. Villous trophoblast apoptosis is elevated and restricted to cytotrophoblasts in pregnancies complicated by preeclampsia, IUGR, or preeclampsia with IUGR. Placenta 2012; 33: 352-359.

23. Huppertz B, Kadyrov M, Kingdom JCP. Apoptosis and its role in the trophoblast. Am J Obstet Gynecol 2006; 195: 29-39.

24. Straszewski-Chavez SL, Abrahams VM, Mor G. The role of apoptosis in the regulation of trophoblast survival and differentiation during pregnancy. Endocr Rev 2005; 26: 877-897.

25. Prives C, Hall PA. The p53 pathway. J Pathol 1999; 187: 112-126.

26. Bieging KT, Mello SS, Attardi LD. Unravelling mechanisms of p53-mediated tumour suppression. Nat Rev Cancer 2014; 14: 359-370.

27. Loughery J, Cox M, Smith LM, Meek DW. Critical role for p53-serine 15 phosphorylation in stimulating transactivation at p53-responsive promoters. Nucleic Acids Res 2014; 42: 7666-7680.

28. Elmore S. Apoptosis: a review of programmed cell death. Toxicol Pathol 2007; 35: 495-516.

29. Sharp AN, Heazell AEP, Baczyk D, Dunk CE, Lacey HA, Jones CJP et al. Preeclampsia is associated with alterations in the p53-pathway in villous trophoblast. PloS One 2014; 9 : e87621.

30. Sharp AN, Heazell AEP, Crocker IP, Mor G. Placental apoptosis in health and disease. Am J Reprod Immunol N Y N 1989 2010; 64: 159-169.

31. Heazell AEP, Sharp AN, Baker PN, Crocker IP. Intra-uterine growth restriction is associated with increased apoptosis and altered expression of proteins in the p53 pathway in villous trophoblast. Apoptosis Int J Program Cell Death 2011; 16: 135-144.

32. Scifres $\mathrm{CM}$, Nelson DM. Intrauterine growth restriction, human placental development and trophoblast cell death. J Physiol 2009; 587: 3453-3458.

33. Hutter S, Knabl J, Andergassen U, Jeschke U. The role of PPARs in placental immunology: a systematic review of the literature. PPAR Res 2013; 2013: 970276.

34. Martínez-Varea A, Pellicer B, Perales-Marín A, Pellicer A. Relationship between maternal immunological response during pregnancy and onset of preeclampsia. J Immunol Res 2014; 2014: 210241 
35. Bouleau S, Grimal H, Rincheval V, Godefroy N, Mignotte B, Vayssière J-L et al. FGF1 inhibits p53-dependent apoptosis and cell cycle arrest via an intracrine pathway. Oncogene 2005 24: 7839-7849.

36. Shieh SY, Ikeda M, Taya Y, Prives C. DNA damage-induced phosphorylation of p53 alleviates inhibition by MDM2. Cell 1997; 91: 325-334.

37. Ashcroft M, Kubbutat MHG, Vousden $\mathrm{KH}$. Regulation of p53 function and stability by phosphorylation. Mol Cell Biol 1999; 19: 1751-1758.

38. Mueller M, Schoeberlein A, Zhou J, Joerger-Messerli M, Oppliger B, Reinhart U et al. Prelmplantation factor bolsters neuroprotection via modulating protein kinase $\mathrm{A}$ and protein kinase C signaling. Cell Death Differ 2015; 22: 2078-2086.

39. Mueller M, Zhou J, Yang L, Gao Y, Wu F, Schoeberlein A et al. Prelmplantation factor promotes neuroprotection by targeting microRNA let-7. Proc Natl Acad Sci USA 2014; 111: 13882-13887.

40. Lehmann SM, Krüger C, Park B, Derkow K, Rosenberger K, Baumgart J et al. An unconventional role for miRNA: let-7 activates Toll-like receptor 7 and causes neurodegeneration. Nat Neurosci 2012; 15: 827-835.

41. Selvamani A, Sathyan $P$, Miranda RC, Sohrabji F. An antagomir to microRNA Let7f promotes neuroprotection in an ischemic stroke model. PloS One 2012; 7: e32662.

42. Cheong AWY, Pang RTK, Liu W-M, Kottawatta KSA, Lee K-F, Yeung WSB. MicroRNA Let-7a and dicer are important in the activation and implantation of delayed implanting mouse embryos. Hum Reprod Oxf Engl 2014; 29: 750-762.

43. Liu W-M, Pang RTK, Cheong AWY, Ng EHY, Lao K, Lee K-F et al. Involvement of microRNA lethal-7a in the regulation of embryo implantation in mice. PloS One 2012; 7: e37039.

44. Banting GS, Barak O, Ames TM, Burnham AC, Kardel MD, Cooch NS et al. CECR2, a protein involved in neurulation, forms a novel chromatin remodeling complex with SNF2L. Hum Mol Genet 2005; 14: 513-524.

45. Pongcharoen $S$, Niumsup $P$, Sanguansermsri D, Supalap K, Butkhamchot $P$. The effect of interleukin-17 on the proliferation and invasion of JEG-3 human choriocarcinoma cells. Am J Reprod Immunol N Y N 1989 2006; 55: 291-300.

46. Barnea ER, Kirk D, Todorova K, McElhinney J, Hayrabedyan S, Fernández N PIF. direct immune regulation: Blocks mitogen-activated PBMCs proliferation, promotes $\mathrm{TH} 2 / \mathrm{TH} 1$ bias, independent of $\mathrm{Ca}(2+)$. Immunobiology 2015; 220: 865-875.

47. Roussev RG, Dons'koi BV, Stamatkin C, Ramu S, Chernyshov VP, Coulam CB et al. Preimplantation factor inhibits circulating natural killer cell cytotoxicity and reduces CD69 expression: implications for recurrent pregnancy loss therapy. Reprod Biomed Online 2013; 26: $79-87$.

48. Itakura S, Ohno K, Ueki T, Sato K, Kanayama N. Expression of golf in the rat placenta: possible implication in olfactory receptor transduction. Placenta 2006; 27: 103-108.

49. Chen H, Meng T, Liu X, Sun M, Tong C, Liu J et al. Long non-coding RNA MALAT-1 is downregulated in preeclampsia and regulates proliferation, apoptosis, migration and invasion of JEG-3 trophoblast cells. Int J Clin Exp Pathol 2015; 8: 12718-12727.

50. Duley L. The global impact of pre-eclampsia and eclampsia. Semin Perinatol 2009; 33 130-137.

51. O'Connor C, Stuart B, Fitzpatrick C, Turner MJ, Kennelly MM. A review of contemporary modalities for identifying abnormal fetal growth. J Obstet Gynaecol J Inst Obstet Gynaecol 2013; 33: 239-245.

52. Handschuh K, Guibourdenche J, Tsatsaris V, Guesnon M, Laurendeau I, Evain-Brion D et al. Human chorionic gonadotropin expression in human trophoblasts from early placenta: comparative study between villous and extravillous trophoblastic cells. Placenta 2007; 28: 175-184.
53. Smyth GK, Yang YH, Speed T. Statistical issues in CDNA microarray data analysis. Methods Mol Biol Clifton NJ 2003; 224: 111-136.

54. Szklarczyk D, Franceschini A, Kuhn M, Simonovic M, Roth A, Minguez P et al. The STRING database in 2011: functional interaction networks of proteins, globally integrated and scored. Nucleic Acids Res 2011 39: D561-D568.

55. Subramanian A, Tamayo P, Mootha VK, Mukherjee S, Ebert BL, Gillette MA et al. Gene set enrichment analysis: a knowledge-based approach for interpreting genome-wide expression profiles. Proc Natl Acad Sci USA 2005; 102: 15545-15550.

56. Kanehisa M, Sato Y, Kawashima M, Furumichi M, Tanabe M. KEGG as a reference resource for gene and protein annotation. Nucleic Acids Res 2016; 44: D457-D462.

57. Kanehisa M, Goto S, Furumichi M, Tanabe M, Hirakawa M. KEGG for representation and analysis of molecular networks involving diseases and drugs. Nucleic Acids Res 2010; 38 : D355-D360.

58. Machinal-Quélin F, Dieudonné MN, Leneveu MC, Pecquery R, Giudicelli Y. Proadipogenic effect of leptin on rat preadipocytes in vitro: activation of MAPK and STAT3 signaling pathways. Am J Physiol Cell Physiol 2002; 282: C853-C863.

59. Benaitreau D, Dieudonné M-N, Dos Santos E, Leneveu M-C, de Mazancourt P, Pecquery R. Antiproliferative effects of adiponectin on human trophoblastic cell lines JEG-3 and BeWo. Biol Reprod 2009; 80: 1107-1114.

60. Perry SW, Epstein LG, Gelbard HA. In situ Trypan blue staining of monolayer cell cultures for permanent fixation and mounting. BioTechniques 1997; 22: 1020-1021 1024

61. Fischer D, Li Y, Ahlemeyer B, Krieglstein J, Kissel T. In vitro cytotoxicity testing of polycations: influence of polymer structure on cell viability and hemolysis. Biomaterials 2003; 24: 1121-1131.

62. Lacasa D, Agli B, Giudicelli Y. Permissive action of glucocorticoids on catecholamineinduced lipolysis: direct 'in vitro' effects on the fat cell beta-adrenoreceptor-coupledadenylate cyclase system. Biochem Biophys Res Commun 1988; 153: 489-497.

63. Bradford MM. A rapid and sensitive method for the quantitation of microgram quantities of protein utilizing the principle of protein-dye binding. Anal Biochem 1976; 72 : 248-254.

64. Prakash GJ, Suman P, Morales Prieto DM, Markert UR, Gupta SK. Leukaemia inhibitory factor mediated proliferation of HTR-8/SVneo trophoblast cells is dependent on activation of extracellular signal-regulated kinase 1/2. Reprod Fertil Dev 2011; 23: 714-724.

(1) Cell Death and Disease is an open-access journal published by Nature Publishing Group. This work is licensed under a Creative Commons Attribution 4.0 International License. The images or other third party material in this article are included in the article's Creative Commons license, unless indicated otherwise in the credit line; if the material is not included under the Creative Commons license, users will need to obtain permission from the license holder to reproduce the material. To view a copy of this license, visit http://creativecommons.org/licenses/by/4.0/

(C) The Author(s) 2016

Supplementary Information accompanies this paper on Cell Death and Disease website (http://www.nature.com/cddis) 